\title{
ASPECTO CITOLÓGICO DE TUMORES INTRACRANIANOS E DO CANAL VERTEBRAL
}

\author{
IVELISE DE SOUZA CAMPOS *, LEILA CHIMELLI *
}

\begin{abstract}
RESUMO - Apresentamos os aspectos citológicos de 137 lesões tumorais operadas por neurocirurgiões, incluindo 12 astrocitomas, 4 astrocitomas anaplásicos, 26 glioblastomas, 7 oligodendrogliomas, 7 ependimomas, 5 meduloblastomas, 8 schwannomas, 7 meningiomas, 13 adenomas de hipófise, 20 tumores metastáticos e 18 tumores diversos e patologias não neoplásicas. Analisamos também citologicamente amostras de tecido nervoso normai obtido de necrópsias, com o objetivo de reconhecê-lo nas biópsias e distingui-lo do tecido neoplásico. Tocio o material foi analisado por esfregacos, que foram comparados posteriormente com os cortes histológicos. Apesar da necessidade de observar os detalhes celilares uos thmores, muitas vezes o arranjo peculiar das células em uma visão de conjunto praticamente permite o diagnóstico da neoplasia no esfregaço.
\end{abstract}

PALAVRAS-CHAVE: tumores intracranianos, tumores do canal vertebral, aspectos citológicos.

\section{Cytologic aspects of intracranial and spinal tumors}

SUMMARY - We present the cytologic aspects of 137 tumors operated by neurosurgeons, incluāing 12 astrocytomas, 4 anaplastic astrocytomas, 26 glioblastomas, 7 oligodendrogliomas, 5 medulioblastomas, 8 schwannomas, 17 meningiomas, 13 pituitary adenomas, 20 metastatic tumors and 18 assorted tumors and nonneoplastic lesions. We have also analysed cytologically samples of normal nervous tissue obtained from autopsies, aiming at its recognition and distinction from the neoplastic tissue in biopsies. The tumors were analysed in smears which were subsequently compared with the histological sections. Although it is important to observe cytological details in the tumor, occasionally cells are arranged in such a way, that an overview of the smear pratically allows the diagnosis of the tumor.

KEY WORDS: intracranial tumors, spinal tumors, cytologic aspects.

A técnica do esfregaço vem sendo utilizada rotineiramente em diversos centros internacionais de neuropatologia em que biópsias por agulha são muito empregadas $1,7,24$ e, também, no Brasil 25 , tendo praticamente substituído a técnica de congelação. No esfregaço o patologista deve familiarizar-se com o aspecto normal, reacional, inflamatório e tumoral das células do sistema nervoso 6,16,28.

Apresentamos neste estudo as características citológicas de lesões operadas por neurocirurgiões e de diversas áreas do tecido nervoso normal.

\section{MATERIAL E MTTODOS}

Ana'isamos 137 esfregaços que incluem 12 astrocitomas, 4 astrocitomas anaplásicos, 26 gliobiastomas, 7 oligodendrogliomas, 5 meduloblastomas, 8 schwannomas, 17 meningiomas, 13 adenomas de hipófise, 20 tumores metastáticos e 18 tumores diversos e lesões não neoplásicas, relacionados no artigo precedente.

*Departamento de Patologia, Hospital Uılversitário Antônio Pedro, Universidade Federal Fluminense (UFF'), Niterói. Aceite: 22-agosto-1992.

Dra. Leila Chimelli - Departamento de Patologia, Hospital Universitário Antônio Pedro Rua Marquês do Paraná 303 - 24030 Niterói RJ - Brasil. 
Além disso, com o objetivo de nos familiarizarmos com o aspecto citológlco do tecido nervoso normal, realizamos esfregaços em fragmentos de leptomeninges, córtex e substancia branca cerebral, tálamo, córtex cerebelar, plexo coróide e hipófise, obtidos de necrópsias de paclentes sem doença neurológica e com pequeno intervalo entre o óbito e a necrópsia.

Os esfregacos eram preparados logo após a retirada do material, usando-se a técnica descrita no estudo precedente.

\section{RESULTADOS}

No tecido nervoso normal observamos que no esfregaca do córtex cerebral há neuronios piramidais, grandes e pequenos, a maioria com nuciéolos evidentes e citoplasma amplo. Há também células gliais sempre menores que os neurônlos, com núcleos arredondados ou ovalados e cltoplasma năo evidente (Flg. 1a) e os vasos são em geral delgados. 0 esfregaco da substancia brance é pouco celular, constituido de células gliais, os astrócitos maiores que os oligodendrócitos, os vasos ato em geral delgados e fundo é flbrilar (Fig. 1b). 0 tálamo mostra neurónios grandes, monomóficos, entremeados por células gliais e vasos com paredes finas. $O$ córtex cerebelar contém células de Purkinje e da camada granulosa (Fig. 2a). As primeiras são volumosas, arredondadas ou piriformes com núcleo claro, nuciélo evidente e citoplasma amplo. Os neurônios da camada granulosa têm núcleos pequenos, arredondados e hipercromáticoş nucléolo evidente (FYg. 2b) e o citoplasma năo é visivel. Há células gliais
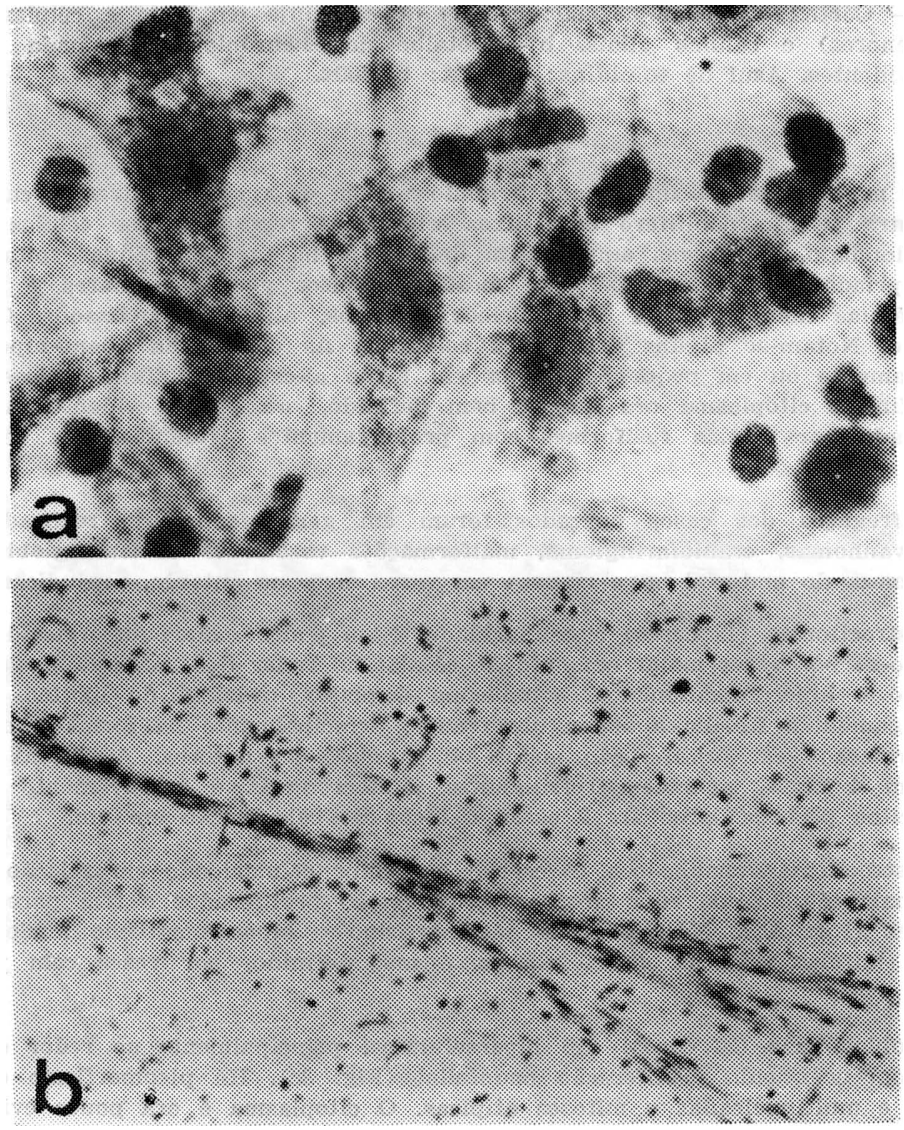

F1g. 1. a - Córtex cerebral normal: neurônios piramidais com nucleolos evidentes, citoplasma amplo; os núcleos menores săo de células gliais. b - Subsitância branca normal: núcleos de células gliais e vaso com ramificaçōes cruzando obliquamente o campo. Azul de toluidina; $\mathrm{a}, 400 \mathrm{x} ; \mathrm{b}, 100 \mathrm{x}$. 


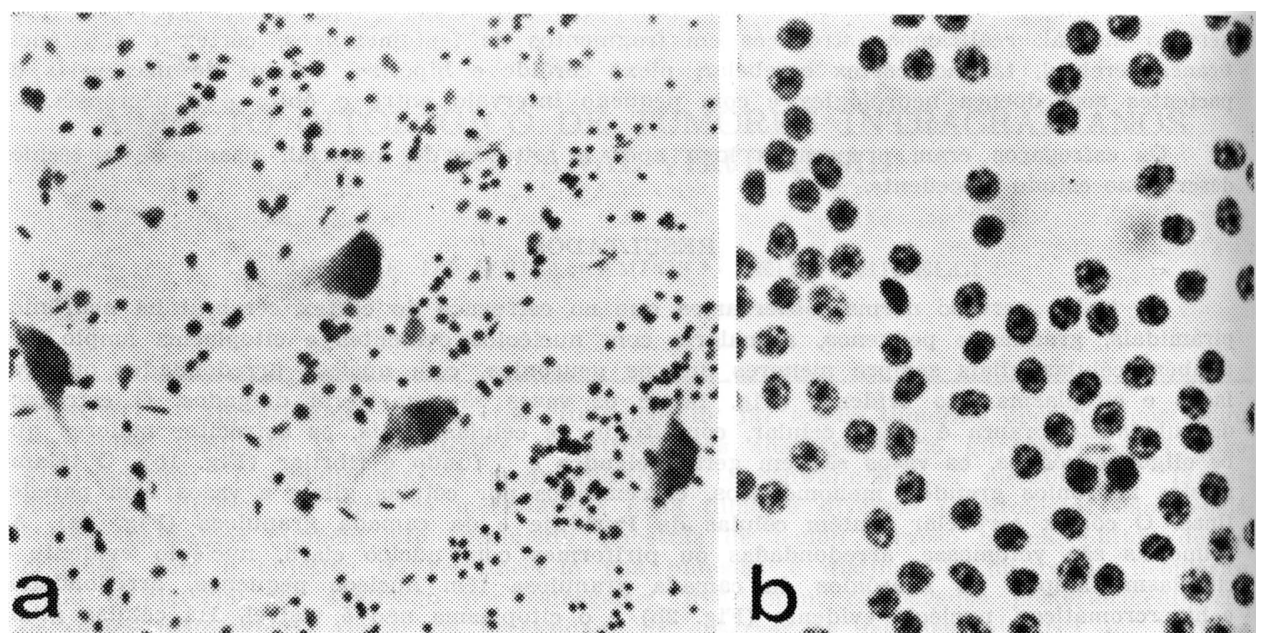

Fig. 2 a - Córtex cerebelar normal: células de Purkinje em melo a células da granulosa (núcieos menores) e células gliais. b - Detalhe dos neurônios da camada granulosa com nucléolos evidentes. Azul de toluidina; a, 100x; b, $400 x$.

com núcieos malores que os da camada granulosa além de vasos de diversos calibres. O plexo coróide mostra padrắo papilifero com eixos vasculares revestidos por células cubóides com núcleo arredondado, citoplasma amplo, bem definido e há também células soltas. A aracnóide não é apropriada para esfregacos, que mostram densos grupos celulares e vasos entre as quais hé células meningotellais com núcleos ovalados, alguns vacuolizados. O citoplasma é mal definido. Notam-se alguns enovelados celulares As células da adeno-hipófise se distribuem difusamente ou em pequenos grupos em torno a capilares. Têm núcleos arredondados, cromatina fina e cltoplasma ora amplo, bem definido, ora pouco evidente. A neuro-hipófise é repregentada por céluias fusiformes com prolongamentos evidentes, por vezes aderidos a vasos.

Os esfregaços dos casos operados foram em geral facilmente realizados, exceto em alguns schwannomas, craniofaringtioma, malformaç̃es vasculares e hemangloblastomas devido a maior firmeza do material ou a riqueza em vasos sem, no entanto, prejudicar o diagnóstico.

Nos astrocitomas (12 casos) a celularidade é um pouco malor que o tecido nervoso normal, notando-se por vezes major acúmulo de células ao redor dos vasos (F1g. 3a). Há discreto pleomortismo e hipercromatismo. O citoplasma $\&$ pouco evidente, de limites imprecisos embora prolongamentos fibrilares sejam observados, principalmente na forma pilocitica. Há discreta neoformaçåo sem pro'iferação endotelial, necrose ou mitoses. As fibras de Rosenthal, presentes em 4 casos, aparecem refringentes. Metacromasia 6 relativamente frequente, havendo línfócitos perfvasculares em 2 casos e focos de calcificaça em um.

Nos astrocitomas anaplásicos (4 casos) há maior celularidade em relaça aos astrocitomas, com mals células ao redor dos vasos que estão proliferados e têm paredes espessas e hipercelulares (FYg. 3b). Há moderado pleomorfismo e hipercromatismo nuclear, células binucleadas e mitoses atípicas $O$ citoplagma $\&$ mal definido, por vezes com prolongamentos nítidos.

Os glioblagtomas (26 casos) são hipercelulares, principalmente ao redor dos vasos neoformados, com acentuada proliferaçáo endotelial (Fig. 3c). Ifé pleomorfismo celular, células bizarras, bi e multinucleadas e mitoses atípicas. $O$ citoplasma 6 ara pouco evidente ora amplo, notando-se hemácias e debrls celulares devido a necrose. Focas de calcificaçăo e infiltrado linfocitário perivascular foram achados ocasionais.

Nos oligodendrog'iomas (7 casos) as células se distribuem difusamente pela lamina, têm núcleos em geral monomórficos, cromatina granular a numerosos capilares (Fig. 4a). $O$ citoplasma é pouco evidente, notando-se halo perinuclear. Mitoses săo raras ou ausientes e ha 

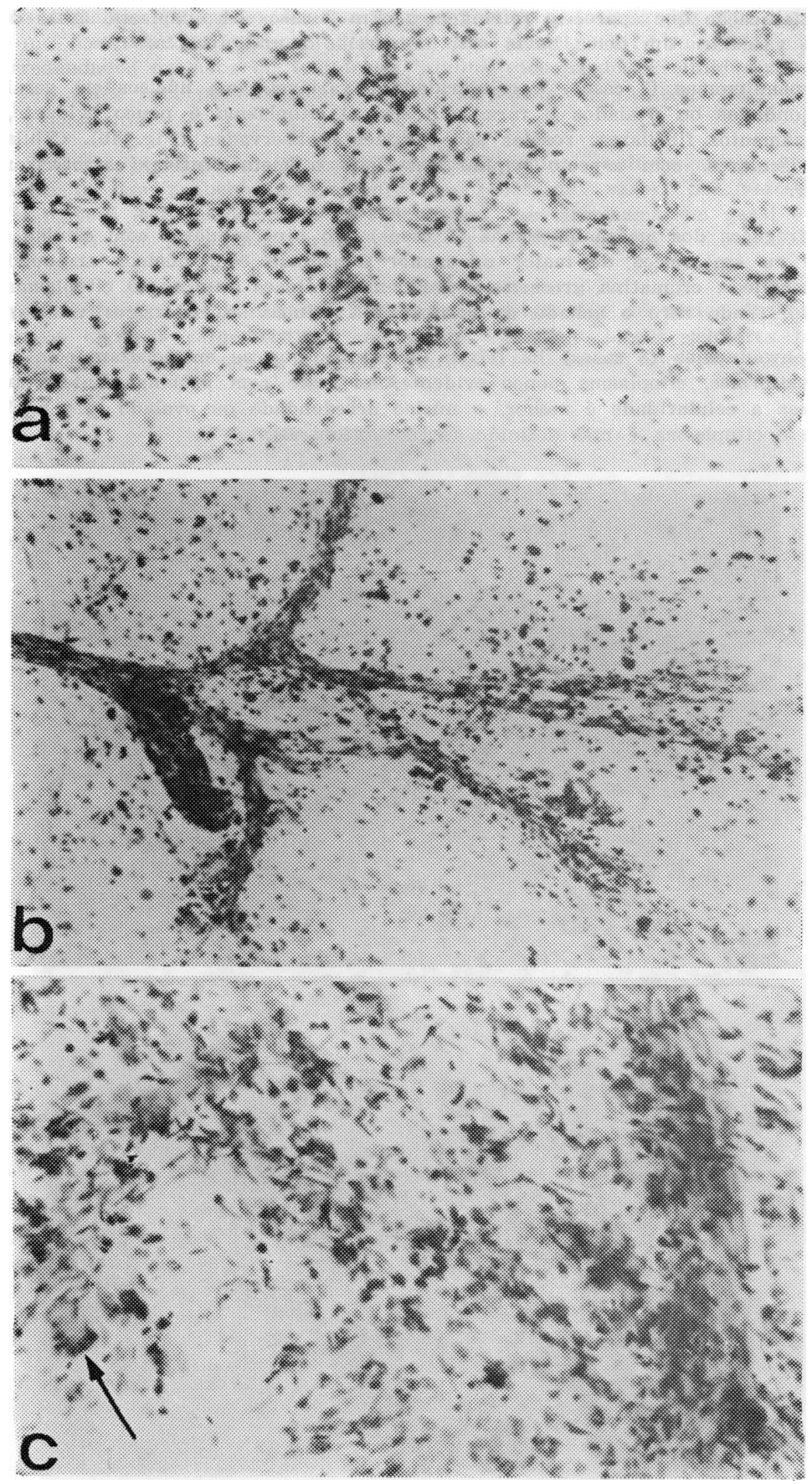

Fig. 3. a - Astrocitoma: celularidade aumentada comparada a substancla branca normal com discreto pleomorfismo; os vasos, embora proliferados, são delgados. b - Astrocitoma anaplásico: as células săo pleomórficas com núcleos hipercromáticos e os vasos têm paredes espessas e hipercelulares, c) - Glioblastoma multiforme: efregaço hipercelular com células pleomóficas, colulas gigantes (seta) e vaso espesso, à direitia, com proliferação endotelial. Azul de toluidina; $a, b, 100 x ; c, 260 x$. 
focos de calcificação que aparecem refringentes. $\mathrm{Em} 2$ casos há anaplasia, áreas de necrose e proliferação vascular. Um deles havia sido submetido a radioterapia.

Nos ependimomas (7 casos) a celưaridade é variável, com núcleos em geral monomórficas, arredondados ou ovalados e raras mitoses. $O$ citoplasma $\&$ pouco evidente, por vezes com prolongamentos fibrllares; rosetas sâo raramente observadaß (Fig. 4b). Cûlulas ao redor de eixos vasculares, com aspecto papilar associado a metacromasia, caracterizam a forma mixo-papilar.

Os esfregacos dos meduloblastomas (5 casos) são hipercelulares com células difusamente distribuidas ou em blocos de maior ou menor densidade com núcleos arredondados, levemente pleomórficos, cromatina grosseira e frequentes mitoses atipicas. $O$ citoplasma é esciasso, mal definido, zlendo raro o achado de rosetas. Há células ao redor dos vasos proliferados.

Nos schwannomas (8 casos) há feixes de célửas que se entrecruzam com núcleos onalados ou fusiformes, citoplasma pouco evidente, às vezes com prolongamentos (áreas Antoni A). Em áreas a celularidade é menor, o núcleo arredondado ou ovalado com moderado pleomorfismo e o citoplasma é mal definido (áreas Antoni B).
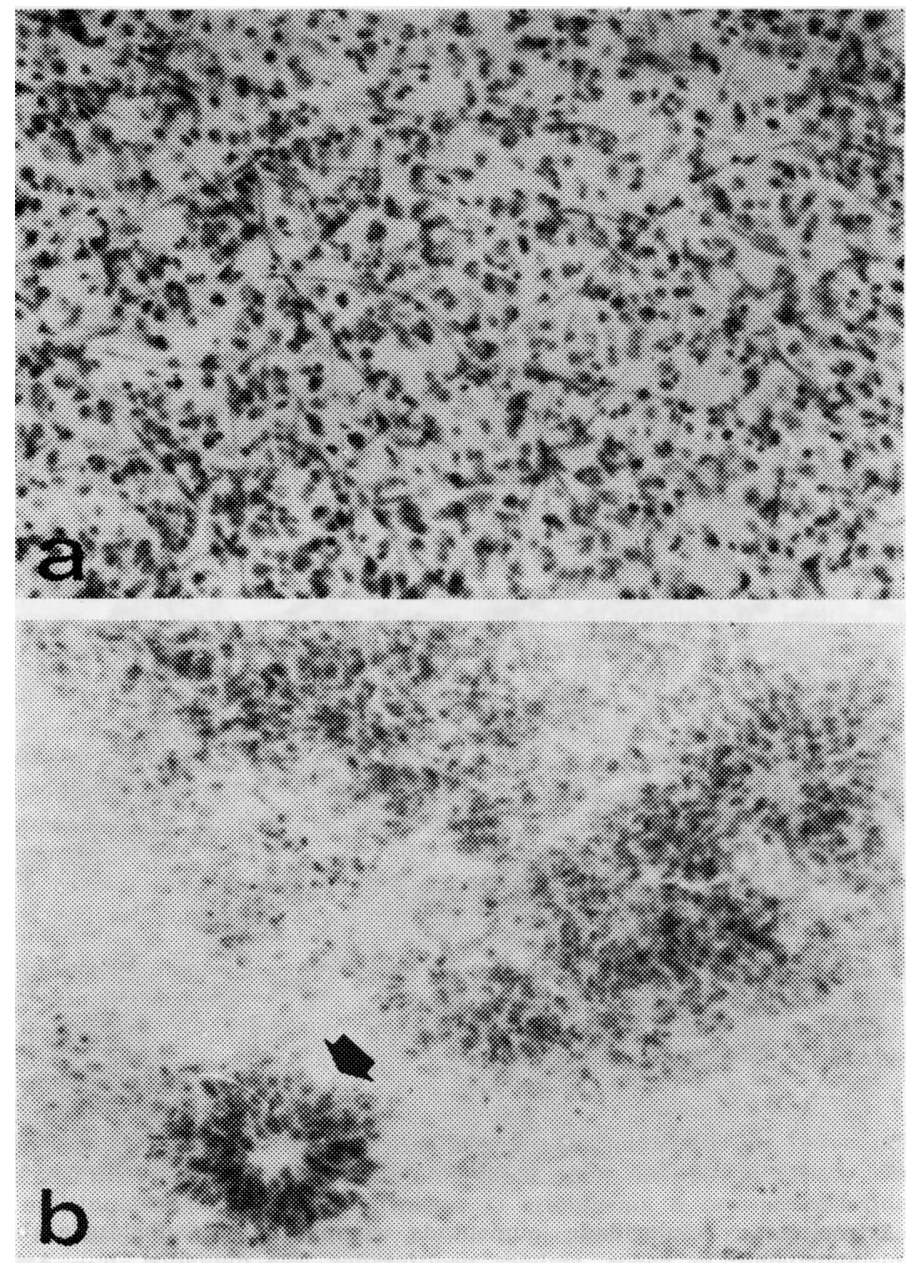

FYg. 4. a - Oligodendroglioma: células difusamente distribuidas, entremeadas por fina trame capilar. b - Ependimoma: monomorfismo celular com formaçăo de roseta (seta). Azul de toluidina; $a, b, 100 x$. 
Os meningiomas (17 casos) formam grupos celulares, interligados por feixes de células (Fig. 5) que por vezes se agrupam formando um sincício em forma de enovelados. Têm núcleos arredondudos ovalados ou fusiformes, alguns vacuolizados e citoplasma escasso, pouco evidente, por vezes com prolongamentos dando ao fundo um aspecto fibrilar. Há também psamomas e mastócitos.

Os adenomas hipofisários (13 casos) mostram células uniformemente distribuidas em camada única ou em pequenos grupamentos ao redor dos vasos, por vezes com aspecto papilar. Os núcleos são monomórficos, arredondados e o citoplasma em geral é amplo, dellmitado, pálido ou com halo claro perinuclear. Neuro-hipófise normal fol observada em alguns cesos.

Os tumores metastáticos (20 cesos), apesar de originados de vários órgăos, apresentam nos esfregaços algumas caracteristicas em comum. Formam blocos celulares bem definidos (Flg. 6) além de exibirem células iso'adas. Rlaramente, esbocam glándulas sugerindo adeno-
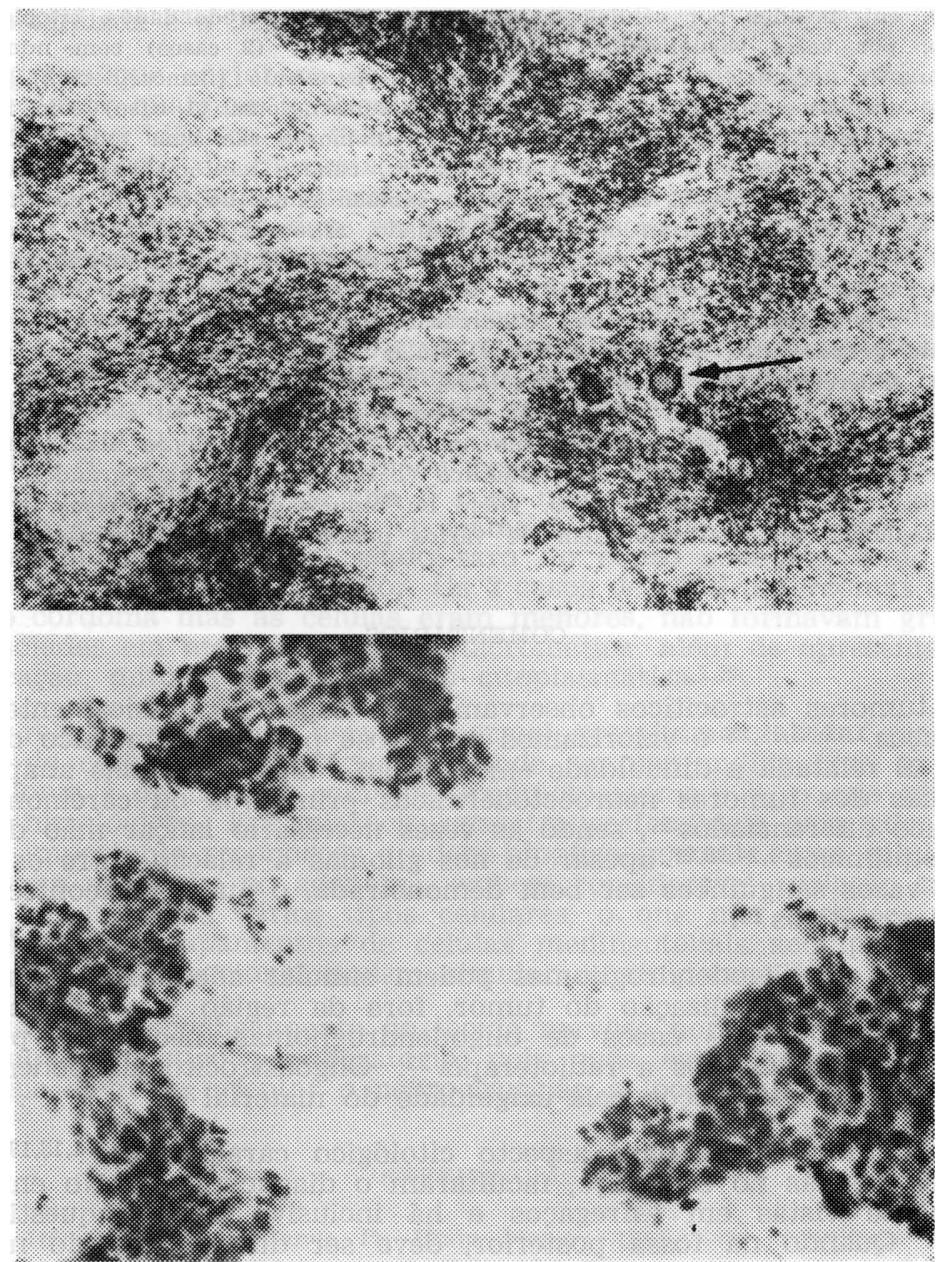

Fig. 5 (no alto). Meningloma: felxes ou grupamentos irregulares de celulas que por vezes se aglomeram de forma concêntrica formando enovelados. Há também um psamoma (seta). Azul de toluidina, $40 \mathrm{x}$.

Fig. 6 (em baixo). Carcinoma metastático: as células neoplásicas, com caracteristicas de células epiteliais, se dispõem em grupamentos bem definidos. Azul de toluidina, 100x. 
carcinoma. Há pleomorfismo celular variável, bi ou multinucleação e mitoses atípicas. Vacuolização citoplasmática é rara, caracterizando a célula muco-secretora. Pigmento cinza-enegrecido é encontrado nos: melanomas. Há também debrisł celulares e necrose.

O grupo dos outros tumores e patologias não neoplásicas (18 casos) incluem: papiloma do plexo coróide ( 1 caso) com células cubóides, monomórficas com citoplasma amplo, dispostas ao redor de feixes fibrovasculares com aspecto papilar; germinoma (1 caso) com células dispostas difusamente pela lâmina, isoladas ou em pequenos grupos, por vezes perivasculares, havendo células pequentas, com núcleos redondos, densos, citoplasma escasso como linfócitos e outras volumosas, pleomórficas, com núcleos hipercromáticos, citoplasma amplo e mitoses atípicas; pineoblastoma (1 caso), tumor neuroectodérmico primitivo ( 1 caso), neurobiastoma ( 1 caso) que são semelhantes ao medulobliastoma; fibromixosarcoma ( 1 caso), cujo estregaço é hipocelular, com núcleos únicos ou múltiplos, moderado pleomorfismo, nucléolos evidenté, citoplasma amplo, fibrilar e intensa metacromasia; nevo de ota (1 caso) que é hıpercelular, com céluias agrupiadas ou perivasculares, discreto pleomorfismo nuclear, sem mitoses e abundante pigmento cinza enegrecido livre ou intracitoplasmatico; hemangioblastomia ( 2 casos) com densos feixes de células com núcleos ovalados ou fusiformes e citoplasma mal definido, €ntremeados por células maiores com núcieos arredondados, citoplasma amplo, pouco nítido, por vezes vacuolizado; malformação vascular (2 casos) com numerosos segmentos vasculares delgados ou espessos, pigmento acastanhado (hemossiderina) livre ou em macrófagos e astrócitoś normais ou reacionais; craniotaringioma (1 caso) com massas celulares densas em cuja periferia células poliédricas escamosas são bem individualizadas e há ainda grupamentos celulares fusiformes ou estrelares, células xantomatosias e pequenos focos de calcificação; plasmocitoma (1 caso) que exibe camada única de células, com núcleos arredondados e excentricos, cromatina de aspecto radiado, aigumas binucleadas, mitoses atípicas e citoplasma bem definido; gliose reacional (1 caso) cujas células têm distribuição difusa ou ao redor de vasos, núcleos arredondados ou ovalados e nucléolo evidente, citoplasma amp:o, homogêneo e prolongamentos evidentes; condrossarcoma (2 casos) com densa matriz metacromátiç com grupamentos celulares e raras células soltas, núcleosi levemente pleomórficos, arredondados, hipercromáticos, ocasional nucléolo, binucleacão, citoplasma amplo, vacuolizado e calcificação foclal; cordoma ( 1 caso) com pequenos aglomerados ou cordões celulares com núcleos ovalados ou arredondados, citoplasma amplo, vacuolizado, densa matriz metacromática e focos de calcificacão; cisto ósseo aneurismátíco (1 caso) com células grandes, multinucleladas, citopiasma amplo e outras menores, mono ou binucleadas, com núcleos ovais ou fusiformes e citoplasma mal definido além de vários polimorfonucleares, hemácią e pigmento acastanhado.

\section{COMENTARIOS}

Nos tumores astrociticos observamos os aspectos classicamente descritos nos esfregaços 1,11,15,18,28 e valorizamos a necrose para o diagnóstico de glioblastoma 17,25. T relatada a dificuldade em distinguir alguns gliomas anaplásicos ou glioblastomas dos tumores neuroectodérmicos primitivos ou carcinomas metastáticos pouco diferenciados 27 , sendo às vezes necessário lançar mão de métodos imuno-histoquímicos 4,24,25,27 apesar de nos gliomas a relação entre os processos gliais e os vasos sanguíneos ser bem demonstrada, o que não acontece nos carcinomas metastáticos 10.

As vezes os oligodendrogliomas podem simular adenomas de hipófise no esfregaço ${ }^{14}$, mas a localização do tumor, fora da região selar, orienta o diagnóstico. Num de nossos casos de oligodendrogliomas, necrose e proliferação endotelial foram atribuídos a radioterapia 22 . Oligoastrocitomas podem não ser diagnosticados em esfregaços pela exiguidade do material 3,5 .

Os ependimomas tinham aspecto citológico característico 1,13,19,20,28. Em um caso, as rosetas no esfregaço, facilitaram o diagnóstico 28 . No entanto, elas são raramente vistas em esfregaços e há inclusive os que questionam sua presença 1. Quando na fossa posterior, deve ser diferenciado do meduloblastoma 11,15,18,20. Nas formas papilares, devem ser diferenciados do papiloma do plexo coróide e do carcinoma papilífero. Critérios citológicos e a localização do tumor ajudam no diagnóstico 26 .

Nos tumores neuroectodérmicos primitivos agrupamos o meduloblastoma, o neuroblastoma e o pineoblastoma por apresentarem aspecto citológico muito semelhante $1,18,20,26$. Os núcleos das células do medulosblastoma parecem maiores 
em esfregaços que em cortes histológicos ${ }^{1}$. Nem todos concordam com o achado de rosetas ou pseudo-rosetas em esfregaços $9,26,28$.

Os schwannomas podem às vezes simular astrocitoma pilocítico 15, o que aconteceu em um de nossos casos.

Todos os meningiomas tinham disposição no esfregaço bastante característica, apesar dos seus vários tipos histológicos $1,11,13,19,20,26,28$. Facilitaram o diangnóstico a vacuolização nuclear, enovelados e psamomas. Alguns podem ser confundidos com gliomas, sobretudo os fibroblásticos 14,19,20,28. Técnicas imunohistoquímicas podem ajudar no diagnóstico 21 .

Não nos preocupamos em caracterizar o tipo histológico dos tumores metastáticos, o que é considerado raramente possível em esfregaços 1,28 , embora alguns mostrassem esboços de glândulas que sugeriam adenocarcinoma 27 . $O$ diag. nóstico de um melanoma foi concluído pelo pigmento que pode ser identificado no esfregaço pela tonalidade: o pigmento melânico é acinzentado, a hemossiderina acastanhada e a hematoidina amarelada 1.

No grupo que englobava os outros tumores e patologias não neoplásicas não observamos qualquer particularidade na maioria dos casos, que tinham aspecto citológico idêntico ao descrito na literatura. Não encontramos referências sobre o aspecto do fibromixossarcoma em esfregaços. Salientamos que a gliose reacional circundando tumores, como craniofaringiomas, metástases e áreas isquêmicas, é intensa e não deve ser confundida com astrocitoma $6,21,24$. As vezes é difícil diferenciar gliose reacional de astrocitoma bem diferenciado. O pleomorfismo nuclear no astrocitoma ajuda nesta diferenciação, assim como os processos citoplasmáticos exuberantes de um astrocitoma pilocítico, que podem diferenciá-lo do astrócito normal 6. Alguns germinomas exibem características celulares similares a um carcinoma indiferenciado de grandes células que, quando no cerebelo, pode simular germinomas, pela semelhança dos linfócitos com células granulosas do cerebelo. Nestes casos, o diagnóstico baseia-se nas características nucleares 18,23,29: as células da camada granulosa têm nucléolo evidente. $O$ diagnóstico diferencial de nevo de Ota é com melanoma devido ao pigmento, mas faltam mitoses e pleomorfismo ${ }^{8}$. O exame histológico neste caso tem características morfológicas clássicas, sendo raro no couro cabeludo e no cérebro ${ }^{12}$, ambos envolvidos no presente caso. Os 2 casos de condrossarcomas eram semelhantes ao cordoma mas as células eram menores, não formavam grupamentos, estando isoladas em meio a matriz metacromática, além de apresentarem bi ou multinucleação, mitoses e vacuolização citoplasmática ${ }^{1.28}$.

Em relação ao tecido nervoso normal ressaltamos ainda que a camada granulosa do cerebelo, nos esfregaços, pode ser confundida com as bordas de um granuloma 15 ou mesmo com um meduloblastoma 11,24, o que não acontece em cortes histológicos. Em microcirurgias transesfenoidais para adenomas hipofisários, é importante reconhecer a adeno-hipófise normal, cujas células além de se agruparem mais que no adenoma, exibem considerável variação no tamanho devido à presença dos vários tipos celulares, o que não acontece nos adenomas 1,2. E ainda, grupamentos de células meningoteliais acompanhando tecido nervoso normal ou reacional podem simular meningiomas $\mathbf{1 5}$.

Portanto, o reconhecimento do tecido nervoso normal em esfregaços é importante no diagnóstico per-operatório, pois pode evitar diagnósticos errôneos de neoplasia além de orientar o neurocirurgião a localizar o tumor.

\section{REFERÊNCIAS}

1. Adams JH, Graham DI, Doyle D. Brain biopsy: the smear techniques for neurosurgical biopsies. London: Chapman and Hall, 1981.

2. Balhuizen JC, Bots GTAM, Schaberg A. The value of cytology in the diagnosis of hypophysea: tumors. Acta Cytol 1974, 18:370-375.

3. Cahill EM, Hidvegi DF. Crush preparations of lesions of the central nervous system: a useful adjunct to the frozen section. Acta Cytol 1985, 29:279-285.

4. Colins VP. Monoclonal antibodies to glial fibrillary acidic protein in the cytologic diagnosis of brain tumors. Acta Cytơl 1984, 28:401-406. 
5. Colombo F, Casentini L, Visona A, Benedetti A. Stereotactic biopsy diagnostic problems: value of cytological and histological examinations. Zbl Neurochir 1982, 43:309-313.

6. Crain BJ, Bigner $\mathrm{SH}$, Johnston WW. Fine needle aspiration biopsy of deep cerebrum: a comparison of normal and neoplastic morphology. Acta Cytol 1982, 26:772-778.

7. Earnest F. Kelly P'J, Scheithauer BW, Kall BA, Cascino TL, Ehman RL, Forbes GS, Axley PL. Cerebral astrocytomas: histopathologic correlation of MR and CT' contrast enhancement with stereotactic biopsy. Radiology 1988, 166:823-827.

8. Enrlquez R, Egbert B, Buliock J, Haven W. Primary malignant melanoma of central nervous system. Arch Pathol 1973, 95:392-395.

9. Gandolfi A. The cytology of cerebral neuroblastoma. Acta Cytol 1980, 24:344-346.

10. González-Cámpora R, Haynes LW, Wellek RO. Scanning electron microscopy of malignant gliomas: a comparative study of glioma cells in smear preparations and in tissue culture. Acta Neuropathol 1978, 41:217-221.

11. Jane JA, Bertrand G. A cytological method for the diagnosis of tumors affecting the central nervous system. J Neuropathol Exp Neurol 1962, 21:400-409.

12. Lever WF, Schawmburg-Lever G. Nevos melanocítico y melanoma maligno. In Lever WF, Schawmburg-Lever G: Histopatologia de la piel. Ed 5. Buenos Aires: Intermedica, 1979, p 571-602.

13. Liwnicz BH, Henderson KS, Mazukawa T, Smith RD. Needle aspiration cytology of intracranial lesions: a review of 84 cases. Acta Cytol 1982, 26:779-786.

14. Marshall LF, Adams H, Doyle D, Graham DI. The histological accuracy of the smear technique for neurosurgical biopsies. J Neurosurg 1973, 39:82-88.

15. McMenemey $\mathrm{WH}$. An appraisal of smear-diagnosis in neurosurgery. AM $J$ Clin Pathol $1960,33: 471-479$.

16. Mouriquand C, Benabid AL, Breyton M. Stereotaxic cytology of brain tumors: review of an eight-year experience. Acta Cytol 1987, 31:756-764.

17. Nelson JS. Tsukada $Y$, Schoenfeld D, Fulling K, Lamarche J, Peress N. Necrosis as a prognostic criterion in malignant supratentorial, astrocytic gliomas. Cancer 1983, 52:550554.

18. Ustertag CB, Mennel HD, Kiessling M. Stereotactic biopsy of brain tumors. Surg Neurol 1980, $14: 275-283$.

19. Papo I, Beduschi A, D'Andrea F, 11 metodo per schiacciamento e striscio nella diagnosi peroperator $\lrcorner$ a dei tumori endocranici. Acta Neurol (Napoli) 1956, 11:1188-1194.

20. Papo I, Colombo F. Possibilità e limite dell'esame estemporaneo per shiacciamento e striscio nella diagnosi peroperatoria dei tumori endocranici. Minerva Neurochir 1959, 3:134-147.

21. Petito CK, DeGirolami U, Earle KM. Craniofaryngiomas: a clinical and pathologica: review. Cancer 1976, 37:1944-1952.

22. Russell DS, Rubinstein LJ. Pathology of tumours of the nervous system. Ed 5. Baltimore: Williams \& Wilkins, 1989, p 871-875.

23. Takahashi M. Citologia prática dos órgãos: sistema nervoso central. In Takahashi M: Atlas colorido de citologia do câncer. Ed 2. São Paulo: Manờe, 1982, p 386-408.

24. Taratuto AL, Sevlever G, Piccardo P. Clues and pitfalls in stereotactic biopsy of the central nervous system. Arch Path Lab Med 1991, 115:596-602.

25. Torres LFB, Collaço LM. Diagnóstico citopatológico de tumores neuroepiteliais pela técnica do esfregaço. Arq Neuro-Psiquiat (São Pauio) 1992, 50:173-179.

26. Wation CW, Hadju SI. Cytology of primary neoplasms of the central nervous system. Acta Cytol 1977, 21:40-47.

27. Willems JC, Alva-Willems JM. Accuracy of cytologic diagnosis of central nervous system neoplasms in stereotactic biopsies. Acta Cytol 1984, 28:243-249.

28. Yashon D, Jane JA. Central nervous system tissue cyto'ogy. Progr Exp Tumor Res $1972,17: 346-362$.

29. Zaharapoulos P, Wong JY. Cytology of common primary midline brain tumors. Acta Cytol 1980, 24:384-390. 